\title{
Membership course or Masters course?
}

\author{
Gary Sullivan and lan R. Jones
}

Doctors who are embarking upon general professional training in psychiatry as Senior House Officers (SHOs) are now faced with making a choice between two types of training schemes. The first type offers training on a membership course aimed primarily at teaching the skills required to pass Part 1 and Part 2 of the MRCPsych. The second type offers training on a university course leading to the award of a Masters degree in psychiatry.

\section{Membership courses}

Membership courses remain the more widespread type of training. They are typically organised locally, and may have some input from a local university department of psychiatry. These courses are monitored by the Royal College of Psychiatrists through visits by the Central Approval Panel (CAP). The Court of Electors and the CAP have published details of the standard expected of training schemes (1994), but it is only now that the College is producing a set of clear criteria for a Collegeapproved MRCPsych course. In one of the few attempts to find out what trainees thought about their training. Castle et al (1994) found that a large majority rated the ability of a CAP visit to bring about significant changes to a training scheme as only 'adequate' or 'poor'.

Membership courses are typically half-day release courses of about $\mathbf{3 0}$ half-days per year for two or three years. They are specifically set up to prepare general professional trainees for membership examinations. Some courses are well organised, fairly comprehensive and include some supervised research (Cox, 1996).

Membership courses in general have been criticised (Castle et al, 1994) for providing inadequate practical help with research and management training in particular. A working party reporting on the issue of research by trainees (Johnston \& Smith, 1991) found that $40 \%$ of trainees were unaware of any available research training, and only $14 \%$ of trainees in district general hospital units felt that they had adequate research training. A majority of trainees $(67 \%)$ were unhappy with their research supervision, particularly those working in peripheral psychiatric units $(87.7 \%)$ and in district general units $(86 \%)$.

\section{Masters courses}

These courses are organised by universities, and are becoming more popular. They are presently offered by Birmingham, Cardiff (Wales), Edinburgh, Keele, Leeds, Manchester and Nottingham universities, UCL, UMDS and the Maudsley. The universities of Bristol and Sheffield are also considering creating Masters courses. The variations in these courses are outlined by Shoebridge \& McCartney (1995). Some are optional, but most also function as the only available training for the MRCPsych examinations and have replaced the membership course completely.

Typically they consist of 25-30 full days per year. The extra time allows the teaching of research methodology, clinical epidemiology, data analysis and statistics, in addition to preparing trainees for the membership examinations. They also require the trainee to conduct a piece of original research, under supervision, and to submit it for examination as a dissertation.

At their best, Masters courses provide a high standard of teaching in all aspects of clinical psychiatry and teach research skills. They encourage trainees to undertake supervised research earlier than they might otherwise do. They facilitate the access of trainees in nonteaching trusts to the university academic department of psychiatry. Trainees have one day per week protected to attend the course during termtime. In addition to the MRCPsych, they allow trainees to complete general professional training (GPT) with a higher degree in psychiatry and possibly publication(s), so producing competitive candidates for higher specialist training (HST).

Nevertheless, reservations have been expressed about Masters courses. The Collegiate Trainees' Committee (CTC) has criticised universities for not offering the mandatory instruction for the MRCPsych examination without trainees signing up for a Masters degree (Davies et al, 1995), even though trainees are not compelled to complete the Masters degree. They have also been criticised for consuming all, or almost all, of the trainee's study 
leave allowance of $\mathbf{3 0}$ days. One could argue that at least the study leave is protected and guaranteed, and that few trainees otherwise use the whole of the study leave time. The cost of Masters courses is variable (Shoebridge \& McCartney, 1995), but they do tend to consume the entire study leave budget for the trainee - at least.

Organisers of Masters courses may tend to focus on the degree as the goal of GPT, rather than the MRCPsych. Some consultants, required to release their SHO for a whole day per week, may be tempted to assume that all training needs are met by the Masters course, although this has not been the general experience in South Wales. Perhaps the main criticism of Masters courses is that they are a lot of work, and may be regarded as an 'extra hurdle' by some trainees. Since GPT and the degree course coincide, a trainee may be faced with writing a dissertation at around the same time as preparing for the Part 2 MRCPsych. Although the academic board may allow some flexibility, this can be taxing for those who require more than one attempt at the membership examination.

\section{Comment}

Masters courses, with a whole day per week for training, probably do provide a more comprehensive training than membership courses, which usually have a half-day per week for training. In addition to preparing trainees for the membership examinations, they are able to provide research training and supervision leading to original research and a dissertation and possibly publication(s).

The question of whether trainees should do research or not during their general professional training is a vexing one which has been argued at length in the Psychiatric Bulletin over the past few years. Trainees do feel that they are under pressure to do research (Johnston \& Smith, 1991). Two papers suggest that trainees are correct to feel this way. Lewis (1991) found that authorship of a publication was the only variable that significantly predicted whether applicants for a senior registrar (SR) rotation in psychiatry at a London teaching hospital were shortlisted. Katona \& Robertson (1993) confirmed this, and found that a publication containing original data was an even stronger predictor of success.

It is not known to what extent trainees deliberately choose to do either a Masters course or a membership course, but geography is probably a major factor. For example, a trainee living in South London might choose between training at Guy's, the Maudsley or St George's without moving house. In contrast, there is only one course in all of South Wales, and that is the Cardiff MSc course, so the only choice is whether one chooses to go and work in South Wales or not.
Transferring between membership schemes is relatively straightforward. Transferring from a membership scheme to a Masters course, or even between Masters courses, may be more difficult because of the need to satisfy university regulations.

Academic psychiatrists may be required to run university courses to justify the use of their academic time for teaching trainees in psychiatry. Realistically, they may only be able to offer a Masters course, and not a membership course. In metropolitan areas, NHS consultants may be more inclined to offer membership courses. For these providers, there are fewer incentives to provide Masters courses.

In an ideal world, both types of training ought to be available, and trainees have a choice. Unfortunately, the current economic climate for universities means that this is unlikely to be attainable. The experience in South Wales is that the development of a Masters course has produced a real improvement in the quality of training, and there would be little enthusiasm for a return to the 'old' membership course.

\section{Acknowledgement}

The authors would like to thank Prof. Anne E. Farmer, UWCM, for her helpful comments on an earlier draft of this paper.

\section{References}

CASTLE, D., ReEve, A., IVINSON, L., et al (1994) What do we think about our training? Psychiatric Bulletin. 18. 357-359.

Court of Electors \& Central APPROVAl PANel (1994) Statement of training schemes for general professional training for the MRCPsych. Psychiatric Bulletin. 18. 514-524.

Cox, J. L. (1996) Course organisers' conference, 5 February, 1996. Psychiatric Bulletin, 20, 571-572.

DAVIES, S., DAVISON, P.. SHARP, C., et al (1995) The Collegiate Trainees' Committee position on structured training. Psychiatric Bulletin, 19, 455-458.

JoHNSTON, S. J. \& SMITH, J. (1991) Research by trainees: a report by the working party of the Collegiate Trainees' Committee. Psychiatric Bulletin, 15, 239-243.

KatonA, C. L. E. \& RoBerTSON, M. M. (1993) Who makes it in psychiatry: CV predictors of success in training grades. Psychiatric Bulletin, 17, 27-29.

LEWIS, S. (1991) The right stuff? A prospective controlled trial of trainees research. Psychiatric Bulletin. 15, 478-480.

SHOEBRIDGE, P. J. \& MCCARTNEY, M. (1995) Masters courses in psychiatry. Psychiatric Bulletin. 19, 555-558.

*Gary Sullivan, Senior Registrar, Department of Psychological Medicine, University of Wales College of Medicine, Whitchurch Hospital, Cardiff CF4 7XB; and Ian R. Jones, Clinical Research Fellow, Department of Psychological Medicine, University of Wales College of Medicine, University Hospital of Wales, Heath Park, Cardiff CF4 4XN 